\title{
Os diferentes processos avaliativos no ensino de ciências: quais são as interpretações dos alunos?
}

Ana Carla Nascimento Alípio professoraanaciencias@gmail.com 0000-0002-5065-6601 Universidade do Estado do Rio de Janeiro.

Tatiana Galieta

tatigalieta@gmail.com

0000-0002-3822-1947

Universidade do Estado do Rio de

Janeiro, São Gonçalo, Rio de

Janeiro. Programa de Pós-

Graduação em Ensino de Ciências,

Ambiente e Sociedade.

\section{RESUMO}

$\mathrm{O}$ artigo apresenta um estudo de caso cujo objetivo central consistiu em averiguar as interpretações dos alunos sobre os diferentes processos avaliativos no contexto da disciplina Ciências. Os dados foram coletados em uma escola pública localizada no estado do Rio de Janeiro por meio de entrevistas com alunos do ensino fundamental e foram analisados: os sentidos sobre avaliação produzidos pelos alunos, as interpretações sobre os diferentes processos avaliativos em aulas de Ciências, os desempenhos nas avaliações em Ciências e sua atitude enquanto eventuais avaliadores. Os resultados mostram que: os alunos fazem uma relação entre o processo de ensino-aprendizagem e as avaliações sem, no entanto, reconhecer os trabalhos em grupo como avaliações; quando colocados na figura de avaliadores, privilegiam testes e provas; e ao justificarem o desempenho na disciplina, identificam o esforço e a dedicação pessoal. Logo, notamos que as interpretações dos alunos estão relacionadas às tradições avaliativas da escola básica. Além disso, pretendemos que os resultados desta pesquisa tenham reiterado a avaliação como uma etapa do processo de ensino e aprendizagem propondo a revisão de seu significado político (além do metodológico) no ensino de Ciências.

PALAVRAS-CHAVE: Avaliação. Interpretação dos alunos. Ensino de ciências. 


\title{
INTRODUÇÃO
}

Essa matéria cai na prova então eu vou estudar. Esta frase já foi dita ou ouvida pela maioria das pessoas em tempos de escola e na universidade. Esta afirmação dita pelos alunos leva-nos a refletir se a avaliação no ensino de Ciências hoje é vista apenas como mais uma tarefa burocrática assumida por alunos e professores. Uma das questões que pode ser colocada, então, está relacionada a qual compreensão esses sujeitos, de fato, têm da avaliação no decorrer da história mais recente da educação brasileira (NUHS; TOMIO, 2011).

Os antecedentes da avaliação se encontram nas épocas da Reforma e Contra Reforma. Na Reforma, na Didática Magna de Jan Amos Komensky, Comenius (1592-1670), e na Contra Reforma, na Ratio Studiorum "Plano de estudos" de 1594 (destinada à educação pelos jesuítas), conforme explicita Sakamoto (2008). O autor ainda enumera três padrões de práticas avaliativas retirados da Didática Magna de Comenius e os outros três da Ratio Studiorum, ambos, transcritos a seguir.

Padrões das práticas de avaliação de Comenius:

\begin{abstract}
De tempos em tempos, interrompendo a lição, deve interrogar um ou outro: o que acabei de dizer? Quer repetir esse período? Em que ocasião aconteceu isso? etc. Isso será útil para toda a classe. Se ficar claro que alguém estava distraído, deverá ser repreendido e punido imediatamente, para que todos se esforcem em prestar mais atenção. (COMENIUS, 2002, p. 212 apud SAKAMOTO, 2008).
\end{abstract}

O professor pessoalmente, como inspetor supremo, deverá dirigir-se ora a um, ora a outro, para verificar, sobretudo a atenção daqueles em quem tem pouca confiança. Por exemplo: pedirá as lições aprendidas de cor a um aluno, a um segundo, a um terceiro e a todos, enquanto todos os outros ouvem. Assim, todos deverão ir preparados para a escola, pelo temor de ser interrogados. (COMENIUS, 2002, p. 213 apud SAKAMOTO, 2008).

O professor também poderá, de quando em quando, olhar pessoalmente os cadernos deste ou daquele, sem ordem específica, e punir aquele que tiver sido negligente ou desatencioso (COMENIUS, 2002, p. 214 apud SAKAMOTO, 2008).

Nas práticas de Ratio Studiorum:

1. A lição para o dia seguinte era cuidadosamente explicada aos alunos.

2. Depois, eles aprendiam de cor.

3. Por avaliações sistemáticas: diariamente, semanalmente, mensalmente.

Segundo Hoffmann (1998), a partir do século XX, principalmente na década de 60 , os cursos de formação de professores brasileiros sofrem grande influência do modelo americano avaliativo criado uma década antes por Ralph Tyler. Este método era conhecido como "avaliação por objetivos". O enfoque deste é a mudança de comportamentos onde o professor inicialmente estabelece objetivos (em grande parte conteudistas) e, em determinados intervalos de tempo, realiza a verificação desses objetivos pelos alunos. Ou seja, a avaliação restringe-se somente ao registro dos resultados. 
Como pôde ser acompanhado nos textos acima, a história da avaliação esteve associada a práticas repetitivas, acríticas e por diversas vezes até punitivas. Sendo assim, até a década de 1970, a Teoria Tecnicista predominava no sistema educacional brasileiro. Além disso, o Brasil passava por uma era política ditatorial, o que se refletia não só nas leis, mas na própria educação brasileira. De acordo com o tecnicismo, a escola só pode melhorar se há um gerenciamento, algo como uma transferência direta dos conceitos industriais de administração para o ambiente escolar (FREITAS, 1997). Da mesma maneira que se produzem novos materiais, novos equipamentos, o aluno satisfatório dentro da sociedade capitalista acaba também por ser mais um produto a ser reproduzido. Desta forma, o papel de "avaliar" tanto o "produto" quanto quem o "fabrica" se mostra evidenciado. Houve naquele momento, de acordo com esse autor, uma resistência inicial, pelo menos para os professores que mantinham uma perspectiva mais crítica na educação, de se trabalhar com a problemática avaliativa.

Já a partir da década de 1980, junto com uma redemocratização governamental, surge uma nova concepção de educação baseada em uma pedagogia histórico crítica. Assim, os professores que anteriormente rejeitavam o tema, passam a trabalhá-lo no campo crítico. Deste momento em diante, surgem várias pesquisas tratando a avaliação sob diferentes aspectos e com base também em distintas tendências pedagógicas. O que ocasionou a maioria desses estudos foi, de acordo com Hoffmann (1998), a tentativa de definição do significado principal da prática avaliativa na ação educacional.

Hoje, em pleno século XXI, este tema continua atual visto que possui uma grande importância na educação brasileira, em seus diversos níveis de ensino. $\mathrm{E}$ embora a questão avaliativa já possua, como foi visto no parágrafo anterior, uma orientação construtivista (onde o objetivo não é a atribuição de notas, mas sim, a facilitação da aprendizagem dos alunos e a orientação do ensino do professor), o papel de destaque dessa, atualmente, ainda se perpetua sob um panorama mais conservador.

Neste significado, majoritariamente ela se apresenta como uma ferramenta capaz de verificar o desempenho dos alunos frente a situações padronizadas, onde as notas são usadas para fundamentar necessidades de classificação dos educandos e possui, em alguns casos específicos, um caráter seletivo explícito tal qual, por exemplo, o Exame Nacional do Ensino Médio - ENEM. Já em outros dispositivos (também de larga escala) tais como, a Prova Brasil, em caráter nacional, e o Programme for International Student Assessment - PISA, de âmbito internacional, apesar de não serem propriamente de aspecto seletivo explícito quanto ao ponto de vista individual, acabam da mesma forma por selecionar, se forem pensados sob a perspectiva de políticas públicas.

Apesar de tamanha relevância, a avaliação tem sido pouco explorada no âmbito do ensino de Ciências e, em particular, de Biologia. De acordo com Amorim e Ern (2002), ao longo das edições do Encontro "Perspectivas do Ensino de Biologia" (EPEB) foram apresentados 776 trabalhos, mas apenas 9 (nove) tratavam da avaliação. Embora este levantamento tenha sido feito há mais de uma década, observamos a carência de investigações sobre o tema, especificamente aquelas voltadas para o Ensino de Biologia. Mais recentemente, e tomando como base o maior evento nacional da área de Educação em Ciências, tomamos como base as atas do IX Encontro Nacional de Educação em Ciências (ENPEC), evento realizado em 2013, nas quais localizamos dentre os 1.060 trabalhos apresentados apenas 22 
que possuíam "avaliação" como palavra-chave. Já no X ENPEC (2015) foram encontrados somente 19 dentre os 1.272 trabalhos presentes nos anais desta edição do evento.

O Brasil, tampouco, é caso isolado na comunidade acadêmica. Poucas investigações sobre avaliação em aulas de ciências e biologia são desenvolvidas internacionalmente. Atualmente, o foco sobre o tema avaliação tem sido os exames padronizados, como o PISA, e seus impactos nas políticas curriculares em países do mundo todo (WYSE et al., 2016). Entendemos que esta lacuna no que diz respeito à discussão sobre a avaliação pela comunidade acadêmica dificulta não somente as discussões coletivas entre pares, mas também o aprimoramento da prática avaliativa no contexto escolar.

Sendo assim, pesquisas sobre a avaliação na disciplina de Ciências são extremamente válidas visto que ampliam a possibilidade de debates sobre o tema. Além disso, consideramos a relevância de se abordar a prática avaliativa sob a perspectiva dos alunos, de modo a por em prática - ao mesmo tempo em que questiona - todo o discurso construtivista visto que estes se tornam, de fato, sujeitos ativos do processo de ensino-aprendizagem. Ademais, saber como o educando encara as diferentes ações para avaliá-lo auxilia o professor a melhorar sua prática pedagógica dentro e fora da sala de aula gerando um ciclo positivo de cooperação para o trabalho entre ambos em prol de um ensino melhor a todos.

Neste sentido, o presente artigo apresenta resultados e discussões derivados de uma pesquisa cujo objetivo central foi averiguar as interpretações dos alunos sobre os diferentes processos avaliativos no contexto da disciplina de Ciências. Tanto as ações avaliativas individuais (prova escrita individual) quanto as coletivas (produção de vídeo, feira de ciências e elaboração de modelos didáticos tridimensionais) foram exploradas em aulas ministradas pela primeira autora e analisadas no âmbito de uma investigação caracterizada como um estudo de caso.

De forma a alcançar o objetivo geral foram definidos os seguintes objetivos específicos: (1) investigar os sentidos produzidos pelos alunos sobre o conceito de avaliação; (2) compreender como os alunos percebem os diferentes processos avaliativos em aulas de Ciências; (3) analisar como os alunos justificam seu desempenho nas avaliações da disciplina e como eles avaliariam quando assumem hipoteticamente a função de professores de Ciências. A seguir descrevemos o nosso referencial teórico base sobre avaliação para discutirmos os resultados desta pesquisa.

\section{DIFERENTES CONCEITOS DE AVALIAÇÃO}

A avaliação segundo Sant'Anna (2013, p. 31) é um "processo pelo qual se procura identificar, aferir, investigar e analisar as modificações do comportamento e rendimento do aluno, do educador, do sistema, confirmando se a construção do conhecimento" aconteceu ou vem ocorrendo com o passar do tempo. De acordo com a autora, a avaliação dirige-se na verdade para as modificações que a aprendizagem provoca no educando e nos objetivos do programa educacional. Sendo assim, para ela isto não inclui apenas o conhecimento do conteúdo em si, mas também nas atitudes expressas pelo aluno. Seus hábitos e interesses, o modo como pensar, agir, ou seja, sua atuação na sociedade. 
Por conseguinte, avaliar não é uma tarefa simples. A avaliação sob o ponto de vista formativo, conforme explicita Hoffmann (1998), parte de dois pressupostos: confiança na possibilidade dos alunos construírem suas próprias verdades e reconhecimento da importância de suas manifestações e interesses. Para a autora:

Avaliar é dinamizar oportunidades de autorreflexão, num acompanhamento permanente do professor, que incitará o aluno a novas questões a partir de respostas formuladas. [...] Uma prática avaliativa coerente com essa perspectiva exige do professor o aprofundamento em teorias do conhecimento. Exige uma visão, ao mesmo tempo, ampla e detalhada de sua disciplina. Fundamentos teóricos que Ihe permitam estabelecer conexões entre as hipóteses formuladas pelo aluno e a base científica do conhecimento. [...] A avaliação deixa de ser um momento terminal do processo educativo (como hoje é concebida). [...] os erros e as dúvidas dos alunos passam a ser considerados como episódios altamente significativos e impulsionadores da ação educativa (HOFFMANN, 1998, p.20-21).

Além disso, é preciso refletir sobre o que Freire (2001) nos diz a respeito desta mediação que ocorre entre o professor e o aluno através da avaliação. Pois, consoante o autor, neste processo o educador passa a buscar informações sobre $o$ aluno, não só em relação aos seus ensinamentos em sala de aula, mas também sobre seu aprendizado enquanto professor e as distintas formas de aprendizagens de seus alunos. Isto por que, assim como o profissional que Ihes ensina, os educandos são sujeitos históricos e a relação destes com o mundo também influencia a maneira como esses sujeitos aprendem.

Ademais, de acordo com Souza et al. (2010), é preciso pensar em uma teoria avaliativa vinculada à realidade brasileira a partir do reconhecimento do compromisso político da escola com as classes populares. Neste sentido, o conceito de avaliação que tradicionalmente tem como alvo o julgamento, seleção e a classificação do aluno necessita, segundo os autores, ser redirecionado para a o julgamento do sucesso ou fracasso do processo pedagógico. Com isso, o processo avaliativo converte-se então, em um instrumento referencial e de apoio às definições de natureza pedagógica, administrativa e estrutural dos agentes escolares. Fato este que possibilitaria aos mesmos decidir quais seriam as ações mais adequadas dentro do projeto educacional a fim de garantir o comprometimento com a aprendizagem do aluno.

No entanto, nem todas as avaliações ocorrem dentro do eixo professor-aluno. Existem àquelas que exteriorizam os muros dos colégios e são concebidas através dos governos das cidades, estados e países. Para Castro (2009), a realização dessas avaliações em larga escala é uma forma de se conhecer melhor a dinâmica dos processos e resultados dos sistemas educacionais. Ela ressalva que esse tipo de processo avaliativo tem se tornado uma constante em países de diferentes culturas e distintas orientações ideológicas de governo. Tendo ainda para a autora, um papel fundamental na prestação de contas a população como é destacado no trecho abaixo. sociedade e de enriquecimento do debate público sobre os desafios da educação no país. [...] Paralelamente aos sistemas nacionais, vários Estados e municípios também organizaram sistemas locais e regionais de avaliação das aprendizagens. Todas essas iniciativas indicam a progressiva institucionalização da avaliação como mecanismo importante para subsidiar 
o processo de formulação e monitoramento de políticas públicas responsáveis e transparentes que devem nortear o aprimoramento de ações de melhoria da aprendizagem. (CASTRO, 2009, p.6).

Portanto, entendemos nesta pesquisa que a avaliação é algo além de uma classificação, ou mesmo, um índice estatístico em meio a exames nacionais. Não que estes exames não sejam importantes no processo de prestação de contas à sociedade e de enriquecimento do debate público sobre os desafios da educação no país conforme destacado por Castro(2009). No entanto, a escola e o professor não podem se preocupar apenas em atender a expectativas positivas em avaliações externas estando atentos para uma formação ampla de seus estudantes. Desta forma, vemos a avaliação como um processo entendendo, ainda, que os termos "instrumentos" ou "tipos" de avaliação - empregados neste artigo - não são usados com a conotação de aspectos isolados do aluno na escola de acordo com uma visão tecnicista. Por isso, eles, assim como a avaliação em si, são encarados como sinônimos de um processo democrático sob o qual sua prática está atenta a construção e a serviço de uma "pedagogia que esteja preocupada com a transformação da sociedade a favor do ser humano, de todos os humanos, igualmente" (LUCKESI, 1996, p.32).

$\mathrm{Na}$ área de Educação em Ciências, por outro lado, a avaliação tem sido abordada sob diferentes perspectivas teóricas as quais refletem como os instrumentos/processos avaliativos têm sido praticamente pensados no espaço da sala de aula de Ciências. A revisão bibliográfica feita por Vieira e Sá (2015), do tipo estado da arte, analisou 6 (seis) periódicos nacionais desde seu número inicial até a última publicação do ano de 2014 e foram localizados apenas 24 artigos. Dentre os vários aspectos analisados, a categoria "A produção e sua distribuição de acordo com o foco temático", revela as perspectivas que têm sido investigadas. São elas: concepções do professor sobre avaliação (2), formação de professores (4), programas em larga escala (5), proposta de avaliação (12) e revisão de literatura (1). Dentre os 24 artigos, destacam-se os de Margareth e Loch (2000), Silva e Moradillo (2002) e Carvalho e Martinez (2005) por serem os únicos a explorar aspectos conceituais da avaliação no ensino de Ciências. Apesar de já serem trabalhos com mais de uma década, estes foram os únicos localizados pela revisão que abordam a avaliação dentro de uma perspectiva processual: encarando os sujeitos (educandos) dentro de um quadro teórico cognitivista relacionado a uma visão do processo educacional como sendo emancipatório (MARGARETH e LOCH, 2000); repudiando a avaliação classificatória e focando na dinâmica da construção dos significados (SILVA e MORADILLO, 2002); ou discutindo aspectos da avaliação formativa, mais especificamente da auto-avaliação (CARVALHO e MARTINEZ, 2005).

As autoras da revisão concluem que o tema avaliação da aprendizagem em trabalhos da área "sinalizam para a complexidade envolvida no ato de avaliar e sobre as implicações da prática avaliativa no processo de ensino aprendizagem" (VIEIRA e SÁ, 2015, p. 8). No entanto, as autoras apontam para a escassa produção e a restrita importância atribuída ao tema pelos pesquisadores quando comparado a outras temáticas recorrentes na literatura. A partir desses resultados entendemos que nossa pesquisa encontra-se em sintonia com a concepção de avaliação que tem sido discutida pelos poucos autores que se debruçam sobre este tema no ensino de Ciências, mas que também busca avançar ao realizar uma investigação empírica cujos sujeitos são alunos da educação básica. 


\section{PROCEDIMENTOS METODOLÓGICOS}

A presente pesquisa é de cunho qualitativo e considerada, especificamente, um de estudo de caso. A pesquisa qualitativa aborda conceitos das Ciências Sociais e Humanas com um nível de descrição e interpretação da realidade geralmente não quantificado. De acordo com Minayo (2012) a pesquisa qualitativa trabalha com o universo dos significados, motivos, valores e atitudes. Esses fenômenos humanos formam um conjunto que vem a ser entendido como parte da realidade social, de modo que este tipo de investigação debruça-se sobre as ações do homem e também sobre as interpretações de suas ações dentro e a partir da realidade vivida e partilhada com seus semelhantes.

O estudo de caso consiste em uma metodologia qualitativa que se caracteriza por sua particularidade pois "focaliza uma situação, um programa, um fenômeno particular" sendo um "tipo de estudo adequado para investigar problemas práticos, questões que emergem do dia a dia" (ANDRÉ, 2008, p. 17/18). De acordo com Stake (1995) existe um tipo de estudo de caso - o estudo de caso intrínseco sobre o qual o pesquisador possui um interesse intrínseco naquele caso particular. Nesta pesquisa, a pesquisadora (primeira autora do artigo) tinha interesse em compreender uma situação na qual ela havia participado diretamente uma vez que as avaliações foram propostas por ela junto aos sujeitos da pesquisa (seus exalunos em anos letivos anteriores ao desenvolvimento da investigação).

Os dados foram coletados na Escola Municipal Ernesto Che Guevara situada no município de Mesquita, baixada fluminense do Estado do Rio de Janeiro, no ano de 2014. A escola possui a organização em três ciclos, com progressão continuada no interior de cada um deles: o primeiro com a educação infantil, o segundo compreende do primeiro ao quinto ano do Ensino Fundamental e o terceiro comporta do sexto ao nono ano do Ensino Fundamental. Atualmente, os educadores desta instituição utilizam quatro conceitos para representar as sínteses de desempenho escolar de seus alunos: I ou Insuficiente; R ou Regular; B ou Bom; MB ou Muito Bom. É importante ressaltar que os professores têm garantida pela direção escolar a autonomia de se valerem de práticas avaliativas que considerarem pertinentes para atribuir os conceitos aos educandos.

Ao longo dos anos de 2012 e 2013 foram desenvolvidos junto a algumas turmas de Ciências, sob regência da primeira autora, diferentes instrumentos avaliativos. Em 2012, com as turmas 601 e 602, foram feitos: produção de vídeo, provas escritas individuais bimestrais e modelos tridimensionais representando a estrutura da Terra. No ano de 2013 (já como alunos da turma 701) eles promoveram um Dia de Promoção da Conscientização da População sobre a Dengue na escola cujas produções coletivas também foram consideradas como avaliações. Ressaltamos que, a partir do nosso pressuposto teórico de que a avaliação consiste em uma etapa do processo de ensino e aprendizagem não sendo, portanto, um momento último ou um produto, estas atividades consistiram em estratégias didáticas que não necessariamente possuíam a função única e primeira de avaliar, mas sim de contribuir neste processo.

Baseando-nos nessas 4 (quatro) experiências avaliativas, desenvolvemos a etapa de coleta de dados com alguns dos alunos do sétimo ano (no ano de 2013) que consistiu em entrevistas. Nestas, de acordo com Lüdke e André (2012), as relações de interação podem ser criadas promovendo uma atmosfera de influência recíproca entre quem pergunta e quem responde o que acaba por facilitar a 
obtenção de um maior número e riqueza de informações. Logo, ao serem entrevistados em duplas ou trios, os alunos poderiam ser influenciados mutuamente uma vez que, as opiniões são construídas socialmente e moldadas na interação com outros sujeitos. Da mesma forma, entendemos que por se tratarem de alunos sendo entrevistados por sua professora alguns sentidos podem ter sido privilegiados em detrimento de outros e que outras interpretações poderiam ser produzidas caso a entrevistadora/pesquisadora fosse outra pessoa. Assim como reconhecemos este fator na produção dos dados, também assumimos as possíveis influências do duplo papel de professora/pesquisadora sobre as análises dos dados.

O primeiro critério para seleção dos alunos sujeitos deste trabalho foi a participação em todos os instrumentos avaliativos abordados nesta pesquisa. 0 segundo critério foi a maior facilidade de coincidir horários para as entrevistas. Os alunos selecionados foram, então, entrevistados em duplas, trios ou individualmente de acordo com a disponibilidade dos mesmos e sem qualquer intenção de que seus agrupados das conversações tivessem a ver com seus desempenhos nas avaliações. Assim, foram entrevistados um total de 7 (sete) alunos nos meses de outubro e novembro de 2013.

As entrevistas seguiram um roteiro inicial com 14 perguntas pré-determinadas caracterizando-se, assim, como entrevistas semi-estruturadas (TRIVIÑOS, 1987). As entrevistas tiveram duração em torno de 30 a 50 minutos tanto para as entrevistas com duplas/trios ou individuais. As informações obtidas nesses encontros foram registradas em audiovisual e também foi utilizado, de modo complementar, um gravador MP4 para que fosse otimizada a percepção do que era falado pelos entrevistados. Posteriormente, todo esse material foi transcrito. Para cada entrevista, os diálogos dos participantes foram organizados em uma tabela com turnos de fala (SINCLAIR; COULTHARD, 1978) conforme explicitado na Tabela 1. Destacamos que nas transcrições (e ao longo de todo o trabalho) foram dados nomes fictícios aos participantes a fim de que lhes fossem preservadas as identidades em acordo com o Termo de Consentimento Livre e Esclarecido assinado por seus responsáveis ${ }^{1}$.

Foi adotada como simbologia nos quadros de transcrição a seguinte formatação: se um participante demorasse mais de cinco segundos para falar isso era representado em seu turno pelo símbolo "[..]". Porém, se ele demorasse mais de dez segundos isso era representado por "[...]".

Tabela 1 - Exemplo de "quadro inicial" utilizado para registro de dados da transcrição das entrevistas.

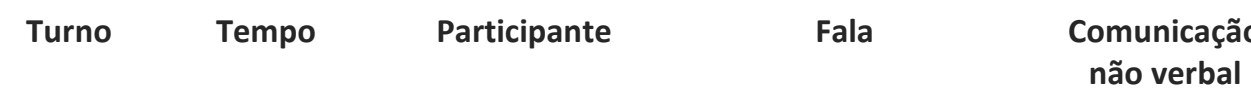

\begin{tabular}{|c|c|c|c|c|}
\hline 1 & 00:00 - 00:50 & Pesquisadora & $\begin{array}{l}\text { Tem uma luz em cima de } \\
\text { você [..] fica ali, acho } \\
\text { que não vai ter luz. Hum, } \\
\text { vai ficar legal. Vai. }\end{array}$ & \\
\hline 2 & 00:51 - 00:53 & Natália & Aqui? & \\
\hline 3 & $00: 53-01: 35$ & Pesquisadora & $\begin{array}{l}\text { Isso. Ah, perfeito! Bom, } \\
\text { vamos começar o } \\
\text { questionário, né? São } \\
\text { perguntas que têm e não } \\
\text { têm a ver com a matéria }\end{array}$ & $\begin{array}{l}\text { Aluna sorri } \\
\text { quando a } \\
\text { pesquisadora }\end{array}$ \\
\hline
\end{tabular}


Posteriormente, os turnos foram resumidos de acordo com critérios como ênfases temáticas e padrões discursivos típicos de uma determinada sequência discursiva. Esses temas, no caso, foram as "perguntas previstas" e as "perguntas enunciadas" no decorrer do tempo da entrevista. Esta organização foi importante uma vez que acabou por simplificar e orientar o cruzamento dos dados obtidos em cada uma das entrevistas no decorrer da análise.

Finalmente, foram elaborados quadros resumos para exemplificar a opinião dos entrevistados sobre determinado tema. Por vezes, dentro desses quadros, apareciam reticências fora dos colchetes "..." no meio das frases. Essas foram usadas para representar os alunos falando em mais de um turno sobre o mesmo assunto (ver Tabela 2). Ou seja, suas principais falas sobre aquela questão são "resumidas" em um único quadro.

Tabela 2 - Exemplo de quadro resumindo a opinião dos alunos sobre um determinado tema (neste caso os critérios avaliativos considerados no Dia de Promoção da Conscientização da População sobre a Dengue).

\section{Exemplos}

Participante

\begin{abstract}
Natália
Helena

Isabela

Sobre a [..] eu acho que você avaliou sobre a explicação que tava dando. Sobre a paciência que tinha com a pessoa. Até timidez que eu tava na hora. Eu achei que ia ser mais difícil, mas não foi tão difícil, foi fácil.

Bruna

Eu acho que a senhora avaliou o que a gente tinha aprendido, o que a gente não tinha aprendido e também nossa evolução.

Deixa eu ver. Nós tínhamos que fazer o trabalho sobre a matéria, o que que nós vimos em sala e depois nós descemos. Então a gente tinha que, nós tínhamos que ter um..., vamos ver, deixa. Avaliou, deixa eu ver o palavreado que a gente tava falando, do jeito que nós estávamos falando, se nós aprendemos, avaliou deixa eu ver. Se nós explicamos direito pras pessoas.

Quando a gente não estava explicando você ia lá e falava: não, é isso aqui assim, assim... Eu gosto.
\end{abstract}

Algumas falas dos participantes foram citadas no corpo do texto de modo a tornar mais claro o ponto de vista de determinado aluno. Esses trechos aparecem aqui (na seção "Resultados e Discussão") em itálico e entre aspas.

Os dados coletados foram, então, analisados com base nos conceitos de avaliação anteriormente apresentados, e com os quais nos filiamos (CORTESE, 2006; FREIRE, 2001; 2005; LUCKESI, 2011; SANT'ANNA, 2013; SOUZA et al., 2010), e organizados em torno de três eixos: 1) Sentidos sobre avaliação produzidos pelos alunos; 2) As interpretações sobre os diferentes processos avaliativos em aulas de Ciências; e 3) Os desempenhos nas avaliações em Ciências e os "alunos avaliadores".

Página | 58

\section{RESULTADOS E DISCUSSÃO}




\section{Sentidos sobre Avaliação produzidos pelos alunos}

Com relação à conceituação de avaliação escolar, o discurso dos alunos trouxe elementos para serem refletidos sobre três questões principais: primeiras impressões sobre a palavra avaliação, suas funções e importância; situações extraescolares em que são encontradas as avaliações; e o que e quem são passíveis de avaliação.

Não se pode negar que a ideia de provas e testes esteve presente na maioria das respostas dos alunos a respeito da palavra Avaliação. No entanto, para Sant'Anna (2013, p. 8), "isto não é propriamente um mal, desde que seja percebida como estímulo para o progresso indicador de que, não tendo ocorrida a aprendizagem, novas estratégias deverão ser utilizadas". Neste sentido, a minoria dos alunos atribuiu a função da avaliação não somente para que eles pudessem "passar de ano" através da verificação de sua "capacidade" ou aprendizado pelo professor, mas também como uma forma do mestre "saber o que fazer" com os alunos.

Ao serem interpelados com a pergunta: Você acredita, que poderia existir escola sem avaliação?, quase todos os entrevistados disseram "não" conforme demonstrado na Tabela 3 abaixo.

Tabela 3 - Opiniões dos alunos sobre a relevância das avaliações escolares.
Escola sem avaliação
Participante
Justificativas

\section{Não}

Helena

Não

Não

Não

Isabela

Não

Não

Natália

Patrícia

Bruna
Página | 59
Acho que não, porque não seria uma [..] poderia até existir, assim, mas não seria uma boa coisa por que como é que o professor vai saber se está ensinando, como que o aluno tá aprendendo? Você não

$$
\text { vai saber, né? }
$$

É. Porque sem avaliação iam perguntar pra ele: você acha que deve passar? Mas vai ter aluno que mesmo sabendo que não...que ele não fez e vai falar eu mereço passar.

É, porque sem avaliação pode passar mil coisas ali no quadro. $\mathrm{Na}$ hora que a professora responder, ele responde também. Entendeu?

[Na hora da prova] Ai ele vai mostrar se ele aprendeu ou se ele não aprendeu.

Vamos lá. Poder poderia, mas não seria bom pros alunos porque o aluno não ia. O professor não ia saber se o aluno aprendeu se o aluno não aprendeu. Nuuuum ia tá sabendo se o aluno tá fazendo aquilo direito.

Precisaria pô. Pra gente arrumar um trabalho bom. 

escola.

Ou seja, no que diz respeito à relevância de haver ou não avaliações nos colégios, seis dos sete participantes desta pesquisa, encontraram alguma explicação positiva para a necessidade desse procedimento dentro do contexto escolar. Este argumento não seria, desta forma, exclusivo de professores ou da equipe pedagógica de maneira geral, de modo que os próprios alunos reconhecem na avaliação uma tarefa essencial à prática docente e ao processo de ensinoaprendizagem.

Por outro lado, o aluno Natan manifestou seu entendimento de que a escola não precisaria de qualquer processo avaliativo uma vez que, sem as avaliações, os alunos evitariam possíveis cobranças quanto ao estudo. Este aluno, em outro momento da entrevista, diz que o conhecimento poderia ser passado naturalmente de pai para filho e, portanto, não haveria nem mesmo a necessidade de haver escolas: Ensinar que nem índio de pai pra filho. Vemos que Natan tem uma visão totalmente diferente dos demais algo que é extremamente interessante visto que põe em xeque o próprio modelo escolar desde o mais tradicional até o mais inovador em prol da "descolarização" (THOMAZ, 2013).

Mudando o foco para os agentes que promovem a avaliação, os alunos disseram ser capazes de avaliar coisas e pessoas fora do âmbito escolar. Porém, dentro do colégio, apesar da maioria deles apontar inspetores, coordenadores, diretores, professores e os outros alunos como pessoas que os avaliam, somente a aluna Natália, cujo conceito é MB em praticamente todas as disciplinas, relatou ser capaz não só de avaliar seus colegas, mas também o professor. $O$ próprio professor... os inspetores me avaliam. Eles vêm comportamento, se o comportamento tiver ruim eles vêm e fala... [avalio o] Comportamento dos meus colegas, a forma como um professor explica a matéria. Tem professor que tem paciência, tem professores que não tem. É assim. Esta interpretação da aluna corrobora o que Cortese (2006) aborda em relação a crianças bem-avaliadas sentirem-se mais autorizadas a avaliar seus avaliadores.

As interpretações sobre os diferentes processos avaliativos em aulas de Ciências

Ao serem indagados sobre quais as formas de avaliação percebidas por eles nas aulas de Ciências, os alunos citaram as mais variadas possíveis, foram elas: provas, trabalhos, trabalhos de casa, testes, comportamento, observação, deveres, vistos no caderno, vídeo e até se o aluno estava sofrendo bullying. Natan e Maurício, por exemplo, entendem que em Ciências os alunos são avaliados de tudo um pouco (Natan) e, ao mesmo tempo, a disciplina avalia em tudo e muito mais (Maurício). Foi interessante isso, pois enquanto em um primeiro momento a palavra avaliação ficou restrita a determinados sentidos estando, na maioria das vezes, relacionados a provas e testes, posteriormente acabaram citando uma diversidade de formas quando thes foi perguntado sobre o modo de avaliação na disciplina de Ciências. Percebemos, desta forma, que os alunos promovem uma ressignificação da avaliação quando o contexto avaliativo está relacionado a uma disciplina específica ou a um professor de Ciências executando o ato de avaliar. processos avaliativos nas aulas de Ciências. O primeiro deles, a prova escrita 
individual, foi mencionado como sendo o mais comum não só em Ciências, mas em todas as disciplinas. Ao serem questionados sobre seus sentimentos em relação à prova escrita de Ciências, os alunos utilizaram termos como: nervosismo, ansiosa, péssimo, não gosto, muito nervosa. Porém, com relação ao aprendizado adquirido com esse instrumento, uma das alunas expressou algo que foi observado na maior parte das demais entrevistas. Helena diz que o estudo para a prova força o aprendizado, segundo ela: é difícil admitir, mas prova a gente encontra algumas vantagens. Tipo, prova a gente tem o teste, pra poder fazer a prova. Tem que estudar porque tem que fazer a prova pra saber como você se saiu, porém a prova em si não aprende, prova avalia. Ou seja, só faz a verificação do "aprendido". O que é bastante coerente, pois para ela, a prova não seria nada além de um "registro" que possui uma finalidade em si mesma. Esta divergência de propósitos da avaliação ainda seria reforçada, segundo Luckesi (2011), por nós professores à medida que dizemos de forma inconsciente aos alunos que eles precisam "melhorar os conceitos" ou "suas notas", ao invés de explanarmos sobre a necessidade de "melhorarem a aprendizagem". Assim, os alunos possuem um mal estar nas provas por se sentirem, talvez, "selecionados" e "classificados" entre "aceitos" e "não aceitos". Conclui-se desta forma que, tanto os alunos quanto os professores precisam ter em mente o real objetivo do ensino dentro do contexto escolar. Pois, "o estudante vai para escola para [ele] aprender e não para ser selecionado" como em um concurso (LUCKESI, 2011, p. 424).

Explorada a questão da individual, o estudo avançou em direção aos processos de cunho coletivo. Todos os alunos afirmaram gostar de trabalhos em grupos, no entanto este tipo de avaliação também sofreu várias críticas negativas como a dependência do comprometimento do grupo para uma real aprendizagem e, ainda, em uma possível dificuldade em diagnosticar o aprendizado de todos os envolvidos neste tipo de avaliação. O lado positivo apontado pelos alunos foi a atividade de colaboração, a partir da discussão em grupo, em prol do crescimento do outro, fazendo com que o próprio processo de ensino-aprendizagem seja percebido por eles. De acordo com Sant'Anna $(2013$, p. 96) esta seria uma "forma cooperativa de desenvolver habilidades mentais através de uma reflexão sistematizada". Isso foi claramente demonstrado pela opinião da aluna Helena (Tabela 4).

Tabela 4 - Formato para subtítulos e legendas. Fragmentos de uma entrevista na qual a aluna Helena comenta a aprendizagem na avaliação em grupo.

Turno

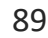

90

91

92
Helena

\section{Participante}

Pesquisadora

Pesquisadora

Helena

Fala

É. Aquele que aprende mais. Fazendo uma avaliação individual ou uma avaliação em grupo? Em grupo, porque já divide assim, um já divide a ideia que o outro tem até pra aprender mais. Você aprende melhor? É em gr

É em grupo porque dá pra dá pra ter uma integração. Assim, a gente fez a crosta terrestre, fez núcleo, fez manto. Eu gostei tanto nessa, como na dengue, como no vídeo. Porque vai o que, 
O primeiro processo avaliativo questionado foi a confecção dos modelos tridimensionais. Este foi alvo de muitas críticas positivas em todos os aspectos, sendo a única avaliação em que não houve pontos negativos apontados por parte dos alunos (Tabela 5).

Tabela 5 - Opiniões dos alunos a respeito da prática avaliativa de elaboração dos modelos tridimensionais sobre a estrutura da geológica do planeta Terra.

Participante

\section{Exemplos}

\begin{abstract}
\begin{tabular}{|c|c|}
\hline Bruna & $\begin{array}{l}\text {... a gente fez a crosta terrestre, fez núcleo, fez manto. Eu } \\
\text { gostei tanto nessa, como na dengue, como no vídeo. }\end{array}$ \\
\hline Helena & $\begin{array}{l}\text { Porque com a prática dá pra gente prestar atenção não é } \\
\text { só a gente copiando, copiando dá para fazer alguma coisa, } \\
\text { mas assim nós fazemos praticando assim... }\end{array}$ \\
\hline Isabela & $\begin{array}{l}\text { Porque enquanto você está fazendo você aprende } \\
\text { também. }\end{array}$ \\
\hline Natália & $\begin{array}{c}\text { Eu acho que era uma avaliação bem diferente. E pode ser } \\
\text { uma avaliação não por escrito, mas sim pelo que estava } \\
\text { fazendo ali... Eu não sabia, tanto que eu aprendi. Eu gostei. } \\
\text { Foi bem divertido. }\end{array}$ \\
\hline Maurício & Foi maneiro. \\
\hline Patrícia & $\begin{array}{l}\text { Eu achei muito legal e aquilo foi uma avaliação. Tanto que } \\
\text { eu lembro que a senhora falou que quem não fizesse ia } \\
\text { ficar sem nota. }\end{array}$ \\
\hline
\end{tabular}

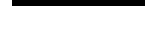
ficar sem nota.

O entendimento de que esta atividade didática e avaliativa foi divertida e contribuiu para a aprendizagem pode estar relacionado ao fato de que essa metodologia caracteriza-se pelo envolvimento direto do aluno em uma atividade prática, na qual os alunos podem utilizar a criatividade artística para se expressarem e produzirem algo que contribui para que se sintam responsáveis pelos seus respectivos aprendizados. O professor, neste caso, foi visto como aquele que avalia e que também orienta visando ao desenvolvimento do trabalho. A fala da aluna Patrícia (Tabela 5), no entanto, mostra a dualidade da elaboração de modelos didáticos como estratégia didática e como instrumento avaliativo já que apesar de ter sido muito legal a aluna recorda também que quem não fizesse ia ficar sem nota. Isso demonstra que os alunos reconheceram o caráter tradicional da avaliação que, ao se constituir como uma atividade para qual é atribuído um "valor", aquele que deixa de fazer pode ser punido.
\end{abstract}

Ademais, segundo os educandos, a confecção de modelos didáticos passa a ser um momento em que eles não precisam estar sentados, copiando tarefas do quadro, podendo interagir mais com seus colegas de classe. Assim, esse processo avaliativo é interpretado pelos participantes da entrevista como algo mais espontâneo e descontraído quando comparado a uma prova escrita, por exemplo.

As percepções dos alunos sobre o vídeo, no entanto, foram distintas pois apesar de grande parte deles terem gostado de produzi-lo, houve a falta de reconhecimento do processo de elaboração do vídeo propriamente como um 
método avaliativo em Ciências. Uma explicação para o ocorrido foi possivelmente devido ao seu tema, "A Escola Ideal", que buscava abordar o ambiente escolar em que vivem, aproximar-se de um currículo humanístico. Este tipo de currículo utiliza a integração como principal forma de organização objetivando a gradativa unidade do comportamento do aluno de modo que os humanistas encorajam experiências que se oponham à fragmentação curricular (SOUZA et al., 2010). Esta linha recebe embasamento na pedagogia Freiriana, a qual entende que a sociedade atual é promove a alienação e a opressão fazendo com que a Educação proporcione, desta forma, contextos humanísticos para a revalidação de valores (SANTOS, 2009). Sendo assim, alunos dificilmente reconhecem esta atividade curricular como componente da dinâmica da disciplina de Ciências. Alguns alunos entenderam a intenção daquele tipo de avaliação como pode ser observado na fala de Bruna: $\mathrm{Nu}$ a nu nu (sic.) foi uma parte sobre o colégio e a outra, que a gente dividiu né? Uma foi sobre o colégio e a outra foi nos lugares. Foi sobre o meio ambiente mais ou menos. Ai, a senhora pediu pra gente desenhar o que a gente queria o que a gente não queria. É uuu, eu acho que sobre Ciências foi mais ou menos isso, né? Que eu me lembre. Porém, em seguida, descartaram a hipótese daquele tipo de atividade integrar a disciplina, como pode ser visto nesta fala de Patrícia na Tabela 6.
Tabela 6 - Fragmentos de transcrição e o reconhecimento da temática do vídeo como algo apropriado para a disciplina Ciências.
Turno Participante
Fala

E depois nós demos notas pra quem produziu os melhores vídeos. Então, vocês acreditam que aquilo também foi uma forma de avaliação ou não? Foi, pra mim foi.

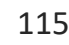

116
Patrícia

Pesquisadora

Isabela

Pesquisadora

Isabela

Patrícia

Pesquisadora

Patrícia

\section{Pra Isabela?}

Forma de avaliação? Pra mim não.

Não, mesmo recebendo notas por aquilo?

Acho que não.

Pra mim foi por que, qual era o título mesmo?

Escola ideal.

Escola ideal porque tipo, não adianta nada falar: ah, a escola ideal eu quero tal tiriri e os cacareca tudo

(sic.) e chegar na hora e não fazer nada, ali. Pra gente, se a gente quer aquilo a escola ideal, a gente tem que fazer.

Por fim, o trabalho coletivo identificado pelos alunos como a atividade em que mais aprenderam e/ou a que mais gostaram dentre os quatro tipos de processos avaliativos mencionados durante a entrevista foi o Dia de Conscientização da População sobre a Dengue. Este parece ter resultado em uma função mobilizadora do aprendizado que se fez perceber no momento em que o aluno visualizou os meios de atingir os objetivos propostos de esclarecer a comunidade escolar diante do que haviam aprendido sobre a Dengue. Diferente dos outros trabalhos em 
grupo, o fato de lidar com o público foi, segundo os alunos, o principal diferencial deste tipo de avaliação. A dificuldade de transformar o que aprenderam em sala e estudaram em casa em ensinamentos a serem compartilhados com o público fez com que seus desempenhos também fossem alvo de autorreflexões por parte dos educandos. Assim, em acordo com Souza et al. (2010), seus progressos e dificuldades foram vistos a partir de seu próprio padrão de desenvolvimento, necessidades e possibilidades.

\section{Os desempenhos nas avaliações em Ciências e os "alunos avaliadores"}

Passado o momento individual sobre cada instrumento, a entrevista detevese a uma finalização com questionamentos sobre o desempenho nas avaliações da disciplina Ciências e também sobre os instrumentos avaliativos escolhidos pelos alunos quando estes assumiam, hipoteticamente, a função de professores de Ciências.

Quanto ao primeiro, ao justificarem o próprio desempenho, e também de seus colegas, diante dos processos avaliativos que tiveram participação na disciplina Ciências, os alunos atribuíram ao esforço pessoal e à sua dedicação os principais fatores para o sucesso ou o baixo desempenho na mesma. Ou seja, não estabeleceram uma relação essencial entre um bom ou mal desempenho e a maneira na qual são avaliados. Sendo assim, o fracasso escolar - ou o baixo desempenho - aparece "como algo exclusivamente intrínseco e não como resultado da complexa interação entre fatores internos e externos" (CORTESE, 2006, p. 92).

Na última parte da entrevista os alunos tiveram que responder à seguinte questão: $E$ se vocês fossem professores de Ciências, como vocês avaliariam seus alunos?, uma vez que buscávamos a inversão de papeis entre eles e o educador/avaliador. A maioria dos alunos demonstrou alguma dificuldade tanto na compreensão da pergunta quanto para expressarem suas opiniões. Desta forma, a pergunta foi repetida por diversas vezes e enunciada de formas diferentes até que alguma resposta fosse formulada pelos alunos. Os entrevistados Maurício e Bruna interpretaram a questão relacionando as estratégias metodológicas adotadas nas aulas de Ciências com os instrumentos avaliativos em si tal qual sua professora de Ciências (Tabela 7).

Tabela 7 - Estratégia metodológica que seria utilizada por alguns alunos na figura de professores de Ciências.

Turno Participante Fala

$\begin{array}{ccc}530 & \text { Pesquisadora } & \text { Ahn Bruna? } \\ 531 & \text { Bruna } & \text { As aulas como a senhora traz assim. } \\ 532 & \text { Maurício } & \text { De vídeo. } \\ 533 & \text { Bruna } & \text { É é [..] que não precisa ficar enchendo de dever no } \\ & \text { Maurício } & \text { É legal a gente brinca, falando, a gente acaba } \\ & & \text { aprendendo sem se ligar. }\end{array}$

Helena, por outro lado, mencionou a avaliação pelo comportamento e pela participação e/ou interesse em sala de aula (Tabela 8). Porém, a aluna demonstrou 
dificuldade na elaboração de sua resposta recorrendo, finalmente, a modelos tradicionais de avaliação como trabalhos e provas. Assim, ela chega a propor que seja feito um trabalho escrito em grupo para que depois seja aplicada uma prova. Esta, por sua vez, seria oral uma vez que, deste modo, o aluno vai ter que estudar antes.

Tabela 8 - Turnos de fala nos quais a aluna Helena pensa formas de avaliação.

Turno Participante Fala

$219 \quad$ Helena

Poxa, ai meu Deus. Como eu avaliaria meus alunos. Eu acho que eu avaliaria mais pelo comportamento. [..] Por que pelo comportamento seria como? Pelo comportamento e trabalho. Nota assim, deixa eu ver. O primeiro por comportamento porque se o aluno não. Um depende do outro. Não é só pra dar uma nota ou bagunça do aluno não. Se o aluno, se o aluno, eu vou tentar fazer o que. Se o aluno tá muito quieto, muito parado, vai lá, fala com ele tenta fazer ele se interessar pela matéria. Tipo assim, por que muitas vezes o professor faz mais do que tá sendo pago. Assim, que que eu ia fazer. Acho que eu ia querer saber o interesse da turma.

Pesquisadora

Helena

Pesquisadora

Helena

Pesquisadora

Helena

Pesquisadora

Helena

Pesquisadora

Helena

Pesquisadora

231
Helena
Então, como assim interesse da turma?

Tipo assim, como que a turma se identifica mais com a matéria.

Mas ai como é que você iria avaliar isso? Como é que vai ser a avaliação pra saber se seus alunos aprenderam ou não?

Como que eu ia saber?

Qual o tipo de avaliação? Se você fosse o professor e tivesse a autoridade que tem o professor, tivesse numa turma, desse a matéria, depois tivesse que ver.

la tacar a prova.

la tacar prova? Mas você criticou tanto a prova como é que você ia usar a prova? Ué, não entendi.

Mas é por isso que eu não gosto.

Mas você, não gostando de prova. Como você admitiu ai. É é é [..]se você fosse professor de Ciências como ia ser a avaliação? la avaliar com uma coisa que você não gosta? Eu ia sim. Eu ia passa o que? Deixa eu ver, tipo um trabalho. Como é que seria aqui, tipo em dupla aí depois ia tacar a prova. Não ia descartar a prova?

Não ia, porque o trabalho nós vamos aprender, a prova é um jeito de, por isso é que existe a 
Pesquisadora

Helena

Pesquisadora

Helena recuperação. Pra mim é assim. A prova é um jeito de saber como você está indo o teste também.

E o trabalho em grupo não tem como você saber como o aluno está indo?

É assim, o trabalho em grupo podemos aprender, um estudo pra quando a gente fizer prova. Tem, tem uma coisa assim diferente porque o trabalho em grupo, deixa eu ver, o trabalho em grupo ou em dupla é como? Deixa eu ver, [..] trabalho em grupo às vezes a depende do jeito também. Tudo bem é bem impressado assim, se for dá computador, se ninguém passar a mão não vai adiantar fazer aquele trabalho, mas se for passar a mão.

Então pra você ver se o aluno aprendeu ou não é só prova?

Não, deixa eu ver. Também a gente podia fazer um diálogo na sala. Tipo, perguntar pro aluno. Uma pergunta tipo uma prova oral.

Além disso, a aluna Patrícia, em particular, disse que utilizaria os testes como um mecanismo de "compensar" todo "sofrimento" sentido por ela em sua vida escolar. Neste caso em específico, percebemos algo que demonstra o quanto as avaliações são percebidas quase que como "punições" colocando a aluna na posição de alguém que foi oprimida durante sua vida escolar. Assim, identificamos na fala da aluna aquilo que Freire (2005) identifica como sendo condição básica da educação bancária: o não reconhecimento da condição de oprimido e, indo além, quando este assume o lugar do opressor acaba se utilizando dos mesmos mecanismos para manter sua posição.

De uma maneira ou de outra, tanto em relação ao desempenho na disciplina quanto em relação à atitude dos alunos investidos na figura de professores de Ciências, os anos submetidos ao ensino tradicional onde é o aluno quem precisa se adequar a instituição escolar parece ser a principal influência na visão dos sujeitos da pesquisa. Essa ideia corrobora ainda com o fato dos educandos escolherem, em sua maioria, provas e testes como os principais instrumentos a serem utilizados caso fossem professores de Ciências.

\section{CONSIDERAÇÕES FINAIS}

A presente pesquisa buscou compreender quais as interpretações dos alunos sobre os diferentes processos avaliativos no contexto da disciplina Ciências, mais especificamente, aquelas relativas a atividades didáticas diversas tais como: construção de modelos didáticos, produção de vídeos, participação em um dia letivo temático, além de prova escrita. Pudemos perceber, de uma forma geral, nas falas dos estudantes entrevistados, que eles percebem o elo que existe entre o processo de ensino e aprendizagem e os trabalhos em grupo. No entanto, apesar dessas atividades coletivas também lhes conferirem conceitos ao longo dos bimestres, eles não as reconhecem de imediato como processos avaliativos, ou entendem que elas são complementares à prova escrita, conferindo-lhes status diferentes. Acreditamos que este entendimento perpassa as definições e compressões dos estudantes sobre a função das avaliações, pois quando eles se 
colocam no papel de avaliadores tendem a escolher provas e testes como as principais estratégias avaliativas a serem utilizadas, mesmo que não gostem de serem avaliados por estes métodos.

Os estudantes não reconheceram a produção de vídeos - estando esta alinhada a uma perspectiva humanística de currículo - como uma atividade que também poderia ser utilizada como instrumento avaliativo (SOUZA et al., 2010). Enquanto que, a confecção de modelos didáticos tridimensionais - geralmente associada a um currículo pautado no ensino de conteúdos - é reconhecida como método avaliativo, além de perceberem esta atividade como tendo algum papel em sua aprendizagem em Ciências. Por outro lado, a maioria dos alunos escolheu como a atividade em que mais aprenderam e a que mais gostaram dentre os quatro tipos de instrumentos avaliativos mencionados durante a entrevista, o Dia de Promoção da Conscientização da População sobre a Dengue. O diferencial neste processo parece ter sido o contato com o público, pois a dificuldade de transformar o que aprenderam em sala e estudaram em casa em explicações a serem apresentadas para outras pessoas fez com que seus desempenhos também fossem alvo de uma autorreflexão sobre o que, de fato, aprenderam com durante a atividade.

No que diz respeito aos seus desempenhos, ao justificarem o próprio resultado, e também de seus colegas, diante das avaliações na disciplina de Ciências, os alunos atribuíram ao esforço pessoal e à dedicação os principais fatores para o sucesso ou o baixo desempenho na mesma. Ou seja, os alunos acreditam que a forma como são avaliados não teria tanta importância, pois a própria vontade do aluno de aprender constitui-se no elemento essencial para a aquisição de boas notas. Estas interpretações revelam uma concepção de educação escolar baseada na meritocracia de acordo com a qual a posição do indivíduo na sociedade (e, mais particularmente, na escola) é consequência de seu próprio mérito não permitindo uma reflexão por parte de estudantes e professores sobre a função legitimadora da meritocracia escolar nas hierarquias econômicas e sociais (BOURDIEU e PASSERON, 1975). A avaliação tem sido, portanto, forte elemento simbólico e mecanismo concreto na propagação de ideologias e de critérios de hierarquização em nossa sociedade já que à escola atribui-se "a responsabilidade de revelar os talentosos e de justificar suas classificações" (VIEIRA et al., 2013, p. 319).

Tanto este quanto outros resultados obtidos na pesquisa levam-nos a relacionar aos sentidos produzidos pelos alunos sobre a avaliação com anos de vida escolar submetida a um sistema pedagógico tradicional, onde o educando é quem precisa ser moldado a fim de se adequar a essa instituição. Neste caso, a avaliação assume um caráter meramente classificatório e pontual, não contribuindo para o processo efetivo de ensino e aprendizagem e, em última instância, para a formação integral do aluno. Por outro lado, reconhecemos que apesar da avaliação ter sido pensada pela professora/pesquisadora como parte do processo de ensino e aprendizagem ainda assim ela está atrelada à quantificação e à atribuição de notas. Isto é compreensível na medida em que pensamos que o conjunto de atividades desenvolvidas e consideradas como instrumentos avaliativos (no caso dos modelos didáticos, da elaboração dos vídeos e das produções coletivas do Dia de Promoção da Conscientização da População sobre a Dengue) visava, além da percepção do que cada aluno havia aprendido, a uma obtenção também de valores que seriam somados à avaliação "tradicional" que é a prova escrita. Isto nos faz refletir que 
apesar das estratégias avaliativas terem sido elaboradas com o intuito de serem inclusivas e processuais, ainda assim, elas estão inseridas em um processo educacional mais amplo no qual a avaliação ainda é algo mensurável e que exclui, uma vez que reprova e mantém ou expulsa da escola aqueles que não têm o desempenho mínimo desejável.

Além disso, compreendemos que o perfil dos sujeitos da pesquisa pode ter sido uma variável determinante nos resultados obtidos, pois, ao selecionarmos aqueles que participaram de todos os instrumentos avaliativos considerados na pesquisa, possivelmente constituímos um grupo de estudantes que podem ter tido mais oportunidades de conseguirem melhores desempenhos na disciplina Ciências que o restante de sua turma. Neste sentido, variáveis como a idade, o tipo de instituição ou mesmo outras estratégias avaliativas não abordadas neste trabalho poderiam ser considerados em outros estudos para que outros aspectos, sob o ponto de vista do estudante, fossem pontuados e aprofundados.

Por fim, esperamos que as discussões apresentadas neste artigo possam contribuir para a prática e reflexão de professores de Ciências e pesquisadores que investigam ou elaboram propostas educacionais sobre avaliação. Além disso, pretendemos que os resultados desta pesquisa tenham reiterado a avaliação como uma etapa do processo de ensino e aprendizagem propondo a revisão de seu significado político (além do metodológico) no ensino de Ciências. 


\title{
The different evaluation processes in science education: what are the interpretations of the students?
}

\begin{abstract}
The article presents a case study whose main objective was to verify the interpretations of the students about the different evaluative processes in the context of science discipline. Data were collected in a public school in the state of Rio de Janeiro through interviews with elementary school students and were analyzed: the senses on evaluation produced by the students, the interpretations of the different evaluative processes in science classes, performances the assessments in science and your attitude as possible evaluators. The results show that: students make a connection between the process of teaching and learning and evaluations without, however, recognize the work group as evaluations; when placed in the figure of evaluators emphasize tests and trials; and to justify the performance in the discipline, identify the effort and personal dedication. Thus, we note that the interpretations of the students are related to evaluative traditions of basic school. In addition, we intend that the results of this research have reiterated the evaluation as a stage of the teaching and learning process proposing the revision of its political (as well as methodological) meaning in science teaching.
\end{abstract}

KEYWORDS: Evaluation. Interpretation of the students. Science education. 


\section{NOTAS}

$1 \mathrm{Um}$ termo de consentimento livre e esclarecido explicando os objetivos, a metodologia da pesquisa, a dinâmica do trabalho e da entrevista em si foi previamente entregue tanto para os responsáveis quanto para a direção da unidade escolar. Somente participaram da pesquisa os alunos cujos responsáveis assinaram o termo atestando sua ciência e autorização dos alunos para a entrevista, já que os educandos eram menores de idade.

\section{REFERÊNCIAS}

AMORIM, M. A. L.; ERN, E. Avaliação como tema nos trabalhos apresentados nos "EPEB". In: VIII Encontro "Perspectivas do Ensino de Biologia". Anais..., 2002.

ANDRÉ, M. E. D. A. de. Estudo de caso em pesquisa e avaliação educacional. 3. ed. Brasília: Liber Livro Editora, 2008.

BOURDIE, P. e PASSERON, J. C. A reprodução: elementos para uma teoria do sistema de ensino. Rio de Janeiro: Francisco Alves, 1975.

CARVALHO, L. M. O de; MARTINEZ, C. L. P. Avaliação formativa: a auto-avaliação do aluno e a autoformação de professores. Ciência \& Educação, v. 11, n. 1, p. 133-144, 2005. Disponível em: < http://www.scielo.br/scielo.php?script=sci_arttext\&pid=S151673132005000100011>. Acesso em: 01 abr. 2014.

CORTESE, B. P. O que dizem os alunos sobre avaliação escolar. Estudos em Avaliação Educacional, São Paulo, v. 17, n. 35, set./dez., p. 69-102, 2006. Disponível em: < http://publicacoes.fcc.org.br/ojs/index.php/eae/article/view/2109>. Acesso em 01 abr. 2014.

CASTRO, Maria Helena Guimarães de. A Consolidação da Política de Avaliação da Educação Básica no Brasil. Meta: Avaliação. Rio de Janeiro, v. 1, n. 3, p.271-296, set./ dez. 2009.

FREIRE, P. Política e Educação. 5. ed . São Paulo: Cortez, 2001. . Pedagogia do oprimido. 47. ed. Rio de Janeiro: Paz e Terra, 2005. 213 p.

FREITAS, L. C. de. Avaliação: Construindo o conceito. Ciência \& Ensino, São Paulo, p. 16-19, dez. 1997. Disponível em: <http://prc.ifsp.edu.br/ojs/index.php/cienciaeensino/article/view/24>. Acesso em: 15 abr. 2014. 
HOFFMANN, J. Avaliação: mito \& desafio: uma perspectiva construtivista. 24ạ ed. Porto Alegre: Mediação, 1998.

LUCKESI, C. Avaliação da aprendizagem escolar: componente do ato pedagógico. São Paulo: Cortez, 2011.

LÜDKE, M.; ANDRÉ, M. E. D. A. Pesquisa em educação: abordagens qualitativas. [Reimpresso]. São Paulo: E.P.U., 2012.

MARGARETH, J.; LOCH, P. Avaliação: uma perspectiva emancipatória. Química Nova da Escola, v. 12, p. 30-33, nov. 2000. Disponível em: <http://qnesc.sbq.org.br/edicao.php?idEdicao=38>. Acesso em: 14 ago. 2015.

MINAYO, M. C. de S. O desafio da pesquisa social. In: DESLANDES, S. F.; GOMES, R.; MINAYO, M. C. de S. (Orgs.). Pesquisa social: teoria, método e criatividade. 32. ed. Petrópolis, RJ: Vozes, 2012.

NUHS, A.C.; TOMIO D. A Prova escrita como instrumento de avaliação da aprendizagem do aluno de Ciências. Estudos em Avaliação Educacional, São Paulo, v. 22, n. 49, p. 259-284, maio/ago. 2011.

SAKAMOTO, B. A. M. A avaliação em questão: Perrenoud e Luckesi. In: Primeiro Simpósio Nacional de Educação e XX Semana da Pedagogia, Anais... 2008. Não paginado.

SANT'ANNA, I. M. Por que avaliar? Como avaliar? Critérios e instrumentos. 16. ed. Petrópolis: Vozes, 2013.

SANTOS, W. L. P. dos. Scientific literacy: a Freirean perspective as a radical view of humanistic science education. Science Education, v. 93, n. 2, p. 361-384, 2009. Disponível em: <http://onlinelibrary.wiley.com/doi/10.1002/sce.20301/abstract>. Acesso em: 18 out. 2015.

SILVA, J. L. P. B.; MORADILLO, E. F. de. Avaliação, ensino e aprendizagem de ciências. Ensaio - Pesquisa em Educação em Ciências, v. 4, n. 1, p. 1-12, 2002. Disponível em: <http://www.portal.fae.ufmg.br/seer/index.php/ensaio/article/view/46/364>. Acesso em: 30 mar. 2014. 
SOUZA, C. P. de; DEPRESBITERIS, L.; FRANCO, M. L. B; SOUSA, S. Z. L. (Orgs.). Avaliação do rendimento escolar. 17. ed. Campinas: Papirus, 2010.

STAKE, E. E. The art of case study research. SAGE Publications, 1995.

THOMAZ, A. Caminhos para a Desescolarização. Educador mídia autônoma e independente, 2013. Disponível em: < http://portaldoeducador .org/desescolarizacao/>. Acesso em: 29 jan. 2014.

TRIVIÑOS, A. N. S. Introdução à pesquisa em ciências sociais: a pesquisa qualitativa em educação. São Paulo: Atlas, 1987.

VIEIRA, L. B. G.; SÁ, L. P. A avaliação da aprendizagem de acordo com as revistas brasileiras da área de Ensino de Ciências. In: X Encontro Nacional de Pesquisa em Educação em Ciências. Anais... 2015. Disponível em: <http://www.xenpec.com.br/anais2015/>. Acesso em: 15 ago. 2015.

VIEIRA, C. M.; BORGES, K. P.; GONZAGA, L. P.; OLIVEIRA, N. D. G. L. de. Reflexões sobre a meritocracia na educação brasileira. Revista Reflexão e Ação, v. 21, n. esp., p. 316-334, 2013. Disponível em: <https://online.unisc.br/seer/index.php/reflex/article/view/3525/2905>. Acesso em 13 de set. 2016.

WYSE, D.; HAYWARD, L.; PANDYA, J. The SAGE Handbook of Curriculum, Pedagogy and Assessment. SAGE Publications, 2016.
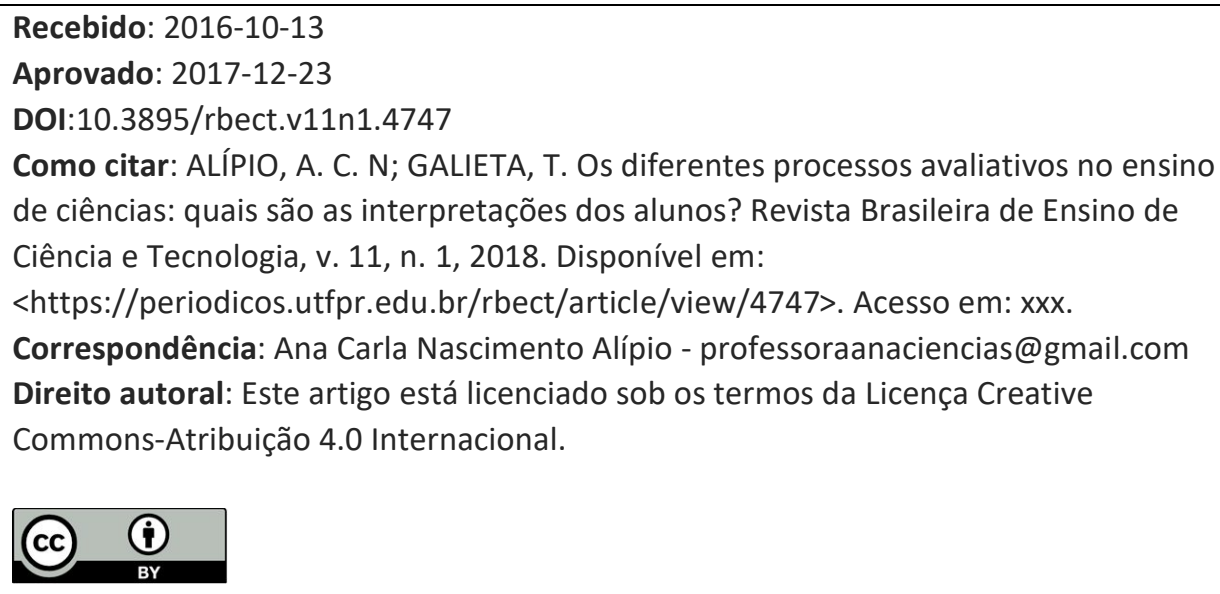